\title{
Evaluation of the potential of three non-woven flax fiber reinforcements: Spunlaced, needlepunched and paper process mats
}

\author{
Martin Nicolas ${ }^{1,3,{ }^{*}}$, Davies Peter ${ }^{2} \stackrel{*}{-}$, Baley Christophe ${ }^{1}$ \\ ${ }^{1}$ Univ. Bretagne-Sud, EA 4250, LIMATB, F-56100 Lorient, France \\ ${ }^{2}$ IFREMER, Centre de Bretagne, BP70, 29280 Plouzané, France \\ ${ }^{3}$ Van Robaeys Frères, 83, Rue Saint Michel, 59122 Killem, France \\ * Corresponding author : Nicolas Martin, email address : nicolas.martin.14.10.87@gmail.com \\ peter.davies@ifremer.fr ; christophe.baley@univ-ubs.fr
}

\begin{abstract}
:
This paper presents results from an experimental study of three types of non-woven preforms (needlepunched, spunlaced and mat manufactured using a paper-making process) intended as composite reinforcement. These are potentially very attractive for transport applications. First, the influence of processing on elementary fiber tensile properties is shown to be limited. Then the preforms are evaluated in polypropylene matrix composites and mechanical properties are determined. The structure of non-woven reinforcements is strongly dependent on the manufacturing route. By varying the fiber content it is shown that the most efficient reinforcement for flax fibers is the mat produced by paper processing. The new spunlaced reinforced composites are shown to have slightly lower tensile properties (15\% lower strength, and $25 \%$ lower stiffness) compared to mat composites at equivalent volume fraction, but further optimization is possible for these materials. Based on the measured constituent properties micromechanics models have been used to estimate composite stiffness. A good correlation is obtained between test results and model predictions.
\end{abstract}

\section{Highlights}

The properties of three flax non-woven reinforcements were studied. Architecture of the nonwovens depends on the manufacturing technique. Influence of the manufacturing process on fiber tensile properties is shown to be limited. Tensile properties of composites depend on non-wovens architecture.

Keywords : Flax fibers, Non-wovens, Composite materials, Polypropylene 


\section{Introduction}

Flax fibers have been shown to possess good mechanical performances as a reinforcement for composite materials (Baley and Bourmaud, 2014) and these properties are constant from one year to the next (Lefeuvre et al., 2014). Oilseed flax fibers may also be used (Pillin et al., 2011), and the replacement of glass fibers by flax can result in a reduction in environmental impacts (Le Duigou et al., 2011). Polypropylene (PP) is a widely used polymer combining mechanical performance with low cost, so combining PP matrix with flax fibers provides recyclable composite materials with interesting properties (Bourmaud et al., 2013; Bourmaud and Baley, 2007). A combination of biodegradable polymers e.g. PLA and flax reinforcement offer the possibility to biodegrade the parts at the end-of-life (Alimuzzaman et al., 2014, 2013).

In plants the flax fibers support the stem and are assembled in bundles (Bourmaud et al., 2015; Morvan et al., 2003). Their properties are very anisotropic (Baley et al., 2006) as a result of their development during plant growth (Gorshkova et al., 2003). A retting step (usually performed by laying the stems on the ground in the field) is necessary in order to facilitate fiber extraction. This step must be closely controlled as it influences the mechanical properties of the fibers (Martin et al., 2013).The stems are then scutched in order to extract the fibers. After scutching, the fibers are in the form of tows. Although the mechanical behavior of these two types of fiber are similar (Martin et al., 2014) their forms are quite different. The scutched fibers are assemblies of fiber bundles with lengths similar to those of the plant (aligned bundles) while the tows are made up of fibers without a particular orientation and containing a fraction of shives. The scutched fibers have a higher commercial value as after a single additional operation (combing to produce a ribbon) threads can be obtained. The tows require further mechanical operations.

Composite reinforcements can be continuous e.g. unidirectional, bidirectional, cross-ply, multidirectional, or discontinuous e.g. random chopped fiber mat. Each reinforcement architecture is designed for a particular domain of application. Fibers with a high aspect ratio and randomly distributed in-plane can be used to manufacture structural parts with a quasi-isotropic behavior. This type of $2 \mathrm{D}$ reinforcement is useful for panel manufacturing, whereas unidirectional fibers are sought for beams.

Several techniques are available to manufacture flax reinforcements. The spunlacing, needle punching and paper- making techniques are three non-wovens industry processes available to produce discontinuous flax fiber preforms. Spunlacing and needle punching are techniques used to give a web of fibers sufficient cohesion 
by mechanical bonding, while paper-making technique (wetlay) allows the production of a web where the fibers are bonded by hydrogen bonds.

The spunlacing technique also called hydroentanglement allows to bond fibers in a web by means of high-velocity water jets. The interaction of the water jets with fibers in the web increases the fibers entanglement and induces displacement and rearrangement of fibers segments in the web. The web of fibers is generally produced by carding.

During the needle punching the fibers of a web are mechanically entangled by reciprocating barbed needles through the web. The web is also generally produced by carding and then cross-lapped to increase the batt density.

The wetlay process is a technique derived from the paper-making technique. The general principle comes as follow. The chopped fibers are first poured in water and then transferred to a stirred water tank. The fibers are deposited on a drainage wire to produce a sheet. This sheet is then dried by suction.

The book of Russell (2006) gives additional information and references about non-wovens manufacturing.

Needlepunching can be used to produce felts with an areal density of $100-4000$ g.m $\mathrm{m}^{-2}$. Spunlacing provides thin non-wovens of areal density 15-400 g. $\mathrm{m}^{-2}$ but experimentally, hydroentangled flax and hemp fabrics up to $1500 \mathrm{~g} \cdot \mathrm{m}^{-2}$ have been produced (Russell, 2006). Both techniques allow different fibers to be mixed e.g. flax and PP to manufacture semi-finished products. The wetlay process or paper process can be used to manufacture mats with an areal density between 50 and $2500 \mathrm{~g} \cdot \mathrm{m}^{-2}$.

Handling of the preforms during composite manufacturing requires a sufficient resistance in the dry state. The resistance of the needlepunched and spunlaced non-wovens is given by mechanical entanglement of the fibers, while the resistance of the wet laid mat is only provided by hydrogen binding between the fibers.

In Europe, the automotive sector is the main user of non-woven reinforced thermoplastic composites, usually for non-structural applications (Chen et al., 2008; Fages et al., 2012; Mieck et al., 1996; Shah, 2013). The main drivers for use of plant fiber composites in automotive applications are the demand for lightweight parts, which leads to a lower fuel consumption, and good recycling possibilities of the components made with thermoplastic polymers, reducing the waste disposal problem (Huda et al., 2008). Other factors that are promoting their applications in the automotive sector are: reduction of greenhouse emissions, competitive 
pricing, technical advantages e.g. longer lifetime of tools, growth opportunities for agriculture, and societal benefits i.e. health and safety improvements. These parts are mainly processed by stamping or compression molding. Weight reduction is sought for interior applications but acoustic and thermal insulation are also required. For the latter parts may be processed with up to $70 \%$ void content.

Thermoplastic matrix composites reinforced with flax non-wovens have been studied previously. Needlepunched flax composites were investigated by (Garkhail et al., 2000; Mieck et al., 1996; Oksman, 2000; Stamboulis et al., 2000). Wet laid flax mats composites were studied by (Bodros et al., 2007; Bos et al., 2006; Roussière et al., 2012). Spunlaced flax reinforced composites were studied by Chen et al. (2008).

Reinforcements with fibers randomly oriented in-plane, or mats, are interesting when quasi-isotropic properties are sought. Roussière et al. (2012) showed that such mats can be produced from flax fibers using paper-making techniques. When these mats are impregnated with a PLA matrix they show tensile properties which are similar to those of glass mat reinforced unsaturated polyester. Knowing the elastic properties of the elementary flax fibers (Roussière et al., 2012) showed that it is possible to estimate the composite properties. This requires knowledge of the in-plane fiber distribution, which is not completely random. The degree of division of fiber bundles and their geometry i.e. the aspect ratio, must also be known.

During composite manufacture the heating cycle will also affect the properties of the fibers (Bourmaud and Baley, 2010) so it is essential to control temperature and time. (Gourier et al., 2014) showed that exposure at $190{ }^{\circ} \mathrm{C}$ for 8 minutes, typical parameters for PP molding, did not significantly affect flax fiber properties. The reinforcing efficiency of flax fibers is strongly dependent on the interface areas between fibers and matrix so bundle division plays an important role (Coroller et al., 2013). This division depends on the technology used to prepare the reinforcement.

In this study three different technologies have been examined, which allow reinforcements to be produced with fibers randomly oriented in the laminate plane: these are non-wovens produced by spunlacing or needlepunching, and mats produced by paper processing techniques. Although these three do not address exactly the same markets they can all be used with natural fibers. The choice of one or another technology depends on the tools available, the cost/performance ratio and the drapability of the preform. Mat is the name generally given to random reinforcements in the composite material industry, particularly short glass fibers, and it can be applied to the paper industry products. 
The aim here is to compare the reinforcement capacities of a modified PP when it is reinforced by layers of flax fibers produced by spunlacing, needlepunching and paper processing. To allow a comparison, it is necessary to know the mechanical properties of elementary fibers, and the microstructure of both preforms and composite materials. First the influence of processing on the reinforcement structure and the mechanical properties of the elementary fibers has been examined. In a second section the reinforcement in the composite and resulting composite properties are studied. The composite stiffness has then been analyzed using micromechanics models.

\section{Materials and methods}

\subsection{Flax non-wovens manufacturing methods}

Three types of flax non-wovens were studied in this paper. Needlepunched and spunlaced non-wovens were manufactured from the same flax batch, random fiber mats were studied as a reference material, manufactured using a paper-making process. The flax plants, of the Suzanne variety, were grown in France in the region Nord-Pas-de-Calais in 2009. At maturity, flax stems were pulled from the ground and laid on the field to allow dew-retting. After harvesting, the flax stems were scutched by Van Robaeys Frères (Killem, France). Scutched fibers were cut to a length of $50 \mathrm{~mm}$ and refined in a Laroche opening machine. After refining, the flax bundles measured $42 \mu \mathrm{m}$ in diameter and $38 \mathrm{~mm}$ in length. The average aspect ratio was approximately 1000 . Both spunlaced and needlepunched non-wovens were manufactured with refined fibers.

Spunlaced non-wovens were manufactured by Norafin Gmbh. Refined flax fibers were dry laid by carding to produce a web, before being consolidated by hydroentanglement. The water jet pressure was up to 100 bar. Following hydroentanglement, water was removed by suction and the non-woven was air $\operatorname{dried}\left(180^{\circ} \mathrm{C}\right)$ before final roll-up. The surface density of the non-woven was 80 g.m².

Needlepunched non-wovens were manufactured by IFTH (Tourcoing, France). Refined flax fibers were dry laid by carding to produce a web. This thin carded web was cross-lapped to increase the thickness of the material before needle punching. The surface density of the non-woven was $200 \mathrm{~g} . \mathrm{m}^{-2}$. 
Flax fibers mats were manufactured by a wetlay process adapted from the paper-making technique. 10 mm chopped fibers were used. The surface density of the non-woven was 100 g.m $\mathrm{m}^{-2}$. This flax batch was studied in a paper published previously (Roussière et al., 2012).

The surface density of the non-woven was measured by weighing a non-woven sample with a surface of $500 \times 500 \mathrm{~mm}^{2}$

Two directions were considered in the non-wovens. The direction of the roll is the machine direction (MD) and the direction of the width is the cross direction (CD).

\subsection{Tensile test on single fibers}

Single flax fibers were hand extracted from fiber bundles originating from random samples taken from the raw fibers, needle punched and spunlaced non-wovens. Single fibers were then bonded onto a paper frame before being clamped in an MTS Synergie RT/1000 tensile machine equipped with a $2 \mathrm{~N}$ load cell. Tensile tests were carried out according to the AFNOR XP T-501-2 standard at controlled temperature $\left(23^{\circ} \mathrm{C}\right)$ and humidity (50\%). Samples were kept at least 48 hours under these conditions prior to the test. Single flax fibers exhibit a nonlinear tensile behavior, so the apparent tensile modulus was measured by calculating the slope of the curve in the last linear part, before failure (Baley, 2002). More than 50 single fibers per samples were tested.

The test gauge length was $10 \mathrm{~mm}$ and crosshead displacement speed was $1 \mathrm{~mm} \cdot \mathrm{min}^{-1}$. Elongation was measured with crosshead displacement. Calculated values of tensile modulus and failure strain include of correction factor taking into account the compliance of the load frame (Defoirdt et al., 2010). This factor take into account the contribution of the elongation of the loading system into. Single fiber apparent diameter was measured at three points along the fiber. The mean value was used to calculate the fiber cross section area considered for tensile properties. The results were analyzed statistically using the Student's t test.

\subsection{Composites manufacturing}

The polymer used as a matrix for composite manufacturing was polypropylene (PP) reference PPC 10642 provided by Total Petrochemicals. In order to improve the compatibility between the matrix and the reinforcements, $4 \%$ by weight of maleic anhydride grafted PP (MA-PP), Orevac CA100 supplied by Arkema, 
was added to the PP matrix. Films of matrix were produced by mixing PP and PPgMA pellets in a Brabender twin screw machine and subsequent film casting.

Composite plates were manufactured by compression molding. The film stacking method was used. Sheets of non-woven and matrix films were stacked and then molded according to the cycle described in Figure 1. The target thickness of the plates was $2 \mathrm{~mm}$.

The target quantity of fiber and matrix to be stacked in the press mold, were calculated considering the mold volume, matrix and fibers density. The different fiber volume fraction were achieved by varying the weight of fiber and matrix. After molding the composite plate was weighted, and the effective fiber weight fraction was calculated. Then the fiber volume fraction were calculating from the fiber weight fraction using a rule of mixture and density of the fiber and matrix.

\subsection{Composites tensile testing}

Tensile tests were performed on dog-bone tensile specimens machined from the composite plates, according to ISO-527-2 on a MTS Synergie RT/1000 tensile machine. The capacity of the load cell was $10 \mathrm{kN}$ and a $25 \mathrm{~mm}$ nominal length extensometer was used. The crosshead displacement speed was $1 \mathrm{~mm} \cdot \mathrm{min}^{-1}$. At least 5 samples were tested for each value and Young's modulus, maximum strength and failure strain were averaged. The Young's modulus was obtained by calculating the slope of the tensile curve in the strain range: $\varepsilon_{1}$ $=0.05 \%$ to $\varepsilon_{2}=0.25 \%$.

\subsection{Optical and Scanning Electron Microscopy (SEM)}

The diameter and length of the flax bundles from the raw material or the non-woven were measured using an optical microscope. More than 200 bundles per samples were measured and the values were averaged (Table 1).

For SEM observations, the samples were sputter coated with a thin gold layer using an Edwards Scancoat Six apparatus, before being examined with a Jeol JSM 6460LV scanning electron microscope. Composite material samples were embedded in an epoxy matrix and polished before coating. We examined the cross section of an intact composite sample with thickness of $2 \mathrm{~mm}$, on a length of $10 \mathrm{~mm}$. For each composite 
sample, a representative image of the whole thickness of a specimen was obtained by stitching together a series of 15 individual high resolution images (x200 magnification). Image analyses were performed using ImageJ software (Schneider et al., 2012).

\section{Results and discussion}

\subsection{Microstructure of the non-wovens}

The non-wovens were studied using SEM in order to assess the organization of the fibers in the dry perform. Figure 2 shows SEM micrographs of the three non-wovens. The left column of Figure 2 shows the surface with observation direction perpendicular to the plane of the reinforcement. The right column of Figure 2 shows SEM micrographs of a slice along the MD direction.

In the needlepunched non-woven, fibers were still gathered in bundles (Figure 2 A and B). A few elementary fibers were observed. Fibers bundles were not straight but were slightly curved. The orientation of the fibers was rather random.

In the spunlaced non-woven, fibers bundles were largely split into elementary fibers and only a few bundles remained (Figure $2 \mathrm{C}$ and D). (Miao et al., 2013) Hydroentanglement is known to cause fibrillation of flax/hemp fibers. The surface of the elementary fibers is clean. The high pressure water jet could have removed a part of the cortex and the middle lamellae. However, the structure was highly entangled. Loops were observed. This could be due to turbulence zones created by the water jets.

In fiber mat, the fibers were gathered into bundles (Figure $2 \mathrm{E}$ and $\mathrm{F}$ ). These bundles were rather straight and randomly placed. There were very few curved fibers.

For the three non-wovens, bundles were oriented in the plane of the preform. No fiber bundles were found in the through-thickness direction. The structure of these non-wovens was therefore mainly two dimensional. Due to the mechanical action of needles crossing the network, the needlepunched non-wovens would be expected to have fibers crossing the plane of the non-woven through thickness. However in our study, the low areal weight of the needlepunched material could explain the limited presence of fibers out of the plane. For the spunlaced non-wovens, the fibers were compacted by the water jet without giving a 3D structure. The 2D 
structure of the mat could be explained by the paper-making process where fibers are laid in the plane of the sheet. From our images, it was not possible to observe a preferential orientation of the fibers in plane. Fiber orientations in plane could have been measured by using a fast Fourier transform (FFT) image analysis algorithm (Xue et al., 2011).

The dimensions of the bundles of the three preforms were estimated by measuring the mean length and the mean diameter of around 200 bundles using optical microscopy (Table 1). The aspect ratio of the needlepunched and spunlaced non-woven bundles were around 1000, compared to 200 for the fiber mat. This could be due to the initial shorter length $(10 \mathrm{~mm})$ and higher diameter of flax mat bundles compared to the two other materials. The results highlight the greater splitting but also the shortening of fiber bundles during the spunlacing process compared to the needlepunching process.

\subsection{Influence of the non-woven manufacturing process on the mechanical properties of the fibers}

The mechanical properties of the fibers were measured by tensile tests on elementary fibers to assess the influence of web forming and web bonding. Tests were carried out on raw fibers and fibers extracted from the non-wovens to compare their mechanical properties (Table 2). For the fiber mat, the short length of the fibers $(10 \mathrm{~mm})$ does not allow tensile tests to be performed on elementary fibers. However, the fiber batch used for flax mat manufacture was characterized previously (Roussière et al., 2012).

The spunlace and the needlepunch processes led to a slight decrease in mechanical properties of the fibers $(\mathrm{P}<0.05)$. The decrease in Young's modulus $(\mathrm{E})$ was $12 \%$. Strength and strain at break were not significantly different $(\mathrm{P}>0.05)$. During the non-woven processes, fibers were carded, and then the network was bonded via high pressure water jet (100 bars) or was run through by needles inducing potential damage. Nevertheless, the drop in tensile properties is small. The properties of the elementary fibers studies here were in the range of values reported in the literature for 50 flax fiber batches (Baley et Bourmaud, (2014), (Table 2).The measurement of the tensile properties of the elementary fibers provides input data for use in micromechanical models.

\subsection{Influence of the non-woven architecture on the mechanical properties of polypropylene matrix composite materials}

3.3.1. Observation of the microstructure of the composite materials 
The cross-section of composite samples was observed by SEM to assess their microstructure.

Composites with a weight fraction of $40 \%$ were examined. Samples were prepared by machining and polishing to allow the observation of the MD direction. For each composite sample, a representative image of the whole thickness was obtained by stitching together a series of 15 individual high resolution images. Figure 3 shows an example of high resolution images for each of the different types of non-wovens. Image analyses were performed using ImageJ software (Schneider et al., 2012). By using an appropriate black and white threshold, these allowed the void content of the composites and the fineness of the fibers bundles of the preforms to be estimated (Table3).

SEM observations showed a good impregnation of the preforms by the matrix. The void content $\left(\mathrm{V}_{\mathrm{p}}\right)$ is low and was evaluated to be less than $1 \%$ (Table 3 ).

Using the mean area of the particles and the number of particles, it is possible to compare the degree of splitting of the flax bundles for each preform. On average, the fibers bundles of the spunlaced non-woven were the most separated. The fibers of the needlepunched non-woven were less split, and the fibers bundles of the mat showed the least splitting (Table 3). The carding process used for needlepunched and spunlaced non-wovens has led to a separation of the bundles, and the water jet bonding of the spunlaced non-woven provided an additional division of the bundles. In comparison, the wet laid process used for the fiber mat processing has maintained the fibers in the form of bundles.

As a result, the fineness of the preforms could be linked to the type of raw fibers and the manufacturing of the non-wovens.

\subsubsection{Influence of the non-woven type on the tensile properties of the composite materials}

\subsubsection{Tensile behavior}

The tensile behavior of the materials was studied for the two directions MD and CD. In the case of the needlepunched non-woven, the orientation of the cross lapped network is close to the CD direction of the nonwoven roll. Therefore, the preferential orientation of the fibers is close to the CD direction. Whereas for the spunlaced non-woven, the MD direction of the roll corresponds to the carded web direction. For the fiber mat, 
the MD direction corresponds to the line direction. Figure 4 shows the tensile curves for the three non-woven reinforced composite materials tested along the MD direction for 4 fiber volume fractions.

The shape of the stress/strain curves was very similar for the three composites. The behavior was nonlinear. Three zones can be distinguished. The behavior is linear at the beginning of the loading, and a change occurs in the slope indicating the first damage. This nonlinearity increases with the load. Finally, the stress decreases with a slight plastic strain before failure of the tensile specimen. In the CD direction, the shape of the stress/strain curves was similar to that shown for the MD direction, and is therefore not included here.

The study of the fracture surfaces of the tensile specimens provided additional information to help understand the tensile behavior of these materials (Figure 5).

Failure surfaces show fiber pull-outs for the three non-wovens. High magnification observation shows a rather good fiber/matrix compatibility highlighted by a cohesive failure, with the presence of matrix on the fiber surfaces and short fiber pull-outs length (Figure 5). The spunlaced non-woven composite appears more homogenous, with shorter fiber pull-out lengths. This could be due to the higher separation of this material.

Fracture surfaces indicate multiple and complex damage mechanisms. These include tensile failure of fibers, fiber pull-outs and matrix failure. As far as we are aware there is no comprehensive study addressing damage mechanisms of flax non-woven reinforced/PP composites in the literature. However, Bourmaud et al. (2013), have studied the damage mechanisms of injection molded flax/PP composites, using tensile tests with in situ SEM observations. The mechanisms were similar to those reported for glass/PP injected composites by Sato et al. (1991). Indeed, for the fibers oriented parallel to the tensile direction, the successive damage steps with increasing load were as follows: First, initiation of micro cracks at fiber tips, then brittle crack propagation along the fiber length at the interface. Failure of fibers without fiber/matrix debonding was also noted. Finally local plastic deformation of the matrix occurred between the cracks and a propagation and opening of the cracks lead to fiber pull-outs and the complete failure of the specimen.

In the case of a mat structure, e.g. a glass mat, fibers are randomly oriented in-plane. Damage initiation is therefore initiated by fiber/matrix debonding of fibers oriented transverse to the loading direction, then fibers more aligned with the longitudinal direction are progressively loaded (Lindhagen and Berglund, 1998). In the case of glass mat/PP composites made of rovings, the splitting-up of fibers within the strands is added to the other damage mechanisms and can lead to large damage areas (Karger-Kocsis et al., 1995). For plant fiber reinforcement, the bundle cohesion is relatively weak (Charlet and Béakou, 2011) and failure can occur within 
bundles (Baley et al., 2006). This adds more complexity to the damage mechanisms of the composites studied here.

\subsubsection{Mean tensile properties}

The mean tensile mechanical properties of the composite materials in the MD direction were measured for four fiber volume fractions (Table 4).

In the MD direction, the Young's modulus and the strength of the three types of composite increased compared to the virgin PP matrix, whereas the strain at break decreased (Table 4). This enhancement of mechanical properties with the fiber volume fraction underlines the reinforcement of the PP/PPgMA matrix by flax fibers, and suggests a satisfactory load transfer between matrix and fibers

The mechanical properties of fiber mat and spunlaced reinforced composites increased linearly with the fiber volume fraction, whereas a threshold was noted for the strength of needlepunched composites for a fiber volume fraction close to $30 \%$. In the MD direction, the best mechanical performances were obtained for fiber mat composites while needlepunched composites gave the lowest mechanical properties. The strain at break of the spunlaced reinforced composite is almost unchanged with higher fiber content compared to the two other materials. This may be caused by the loops and entanglements present in the spunlaced material, which maintain specimen integrity to higher strains.

The mean tensile mechanical properties of the composite materials in the $\mathrm{CD}$ direction were also measured for four fiber volume fraction (Table 5). For the three composites, the Young's modulus again increased with the fiber volume fraction. For the spunlaced and needlepunched composites, the strength of composites increased with the fiber volume fraction, while for the fiber mat composites, a threshold was reached for a fiber volume fraction of around $30 \%$ and the strength decreased for a higher volume fraction. For the CD direction needlepunched composites showed the best strength, while spunlaced and fiber mat composites showed lower performance.

Ericson and Berglund (1992) studied the tensile properties of randomly oriented glass mat/PP composites manufactured by thermo-compression. The strength of those composites reached a threshold for a fiber volume fraction of $20 \%$.

Ausias et al. (2013) also reported a decrease of tensile strength for short flax fibers/PP injected composites above a fiber volume fraction of $30 \%$. 
The threshold noted for the strength while increasing fiber volume fraction here can be compared to the tensile behavior of a ply loaded in the transverse direction. In this case, the failure originates from stress concentrations in the matrix surrounding the fibers. Kies (1962) defined a model to describe the evolution of stress concentrations by considering a representative element of a laminate loaded in the transverse direction. The author showed the increase in stress concentrations as a function of fiber volume fraction due to the decrease in space between fibers. In the case of non-wovens, increasing the fiber volume fraction also increases the amount of fibers loaded off-axis and decreases the spacing between them. The latter could explain the thresholds observed for the strength of composites. Furthermore, increasing the fiber volume fraction over the limit could lead to damage in fiber rich zones.

Tensile properties were dependent on the stress direction. The mechanical properties of spunlaced and mat reinforced composites were higher in MD than in CD while the opposite was observed for the needlepunched reinforced composites. This is due to the cross lapping of the web before needlepunching. Therefore, the preferential orientation of the fibers is close to the CD direction (Mieck et al., 1996). These differences also highlight the differences in anisotropy of mechanical properties of the three non-woven composites.

In order to rank the material properties while overcoming their anisotropy, the tensile properties of the non-woven composites were compared considering the average properties between the MD and CD directions, calculated as the sum of MD and CD properties divided by two (Figure 6). The mat reinforced composite gave the best strength and stiffness in combination with PP. The strain at break did not vary with the fiber volume fraction.

The mechanical properties of the elementary fibers were similar for the three non-wovens, hence the difference in mechanical properties measured for the composite materials could come from the layout and orientation of the non-woven assemblies. The higher degree of splitting of the fiber bundles of the spunlaced composite did not lead to a gain in performance compared to the needlepunched material. The lack of organization and the entanglement of the bundles (loops) did not allow the former to benefit from the high aspect ratio of the fibers. However, the spunlacing parameters were not set to manufacture a composite reinforcement, it may therefore be possible to improve the structure of these materials by tuning the process parameters. Despite shorter lengths and lower aspect ratio, the fiber mat benefits from the presence of straighter fibers. For the 
needlepunched non-wovens, the bundles were longer but thinner and this led to curvature of the bundles and lower mechanical properties.

Table 6 shows published data for non-woven composites. For the same fiber volume fraction, the Young's modulus values of these materials are very different. The data presented in the present paper show that the mechanical properties of composites reinforced by spunlaced flax non-wovens can be much higher than results from previous studies (Chen et al., 2008). Nevertheless, the work of Chen et al. (2008) did not detail if the composites were fully impregnated. The properties of the flax mat composites tested here were slightly higher than the values reported in the literature, however the previous studies did not specify the direction of the preforms considered for the tensile test, so comparisons are not reliable. The properties of composites reinforced with needlepunched non-wovens tested here were lower than the literature data. The difference could be explained by a number of process parameters e.g. fiber length and diameter, crosslapping, needle penetration and density, or the areal weight of the preform.

\subsubsection{Comparison of measured and predicted stiffness values of the composite materials using a micromechanical model}

In order to examine how fiber properties transfer to non-woven composites it is interesting to evaluate properties using micromechanics models. The Halpin-Tsai model and Tsai-Pagano approach were used to estimate the theoretical stiffness of these composite materials. Knowing the elastic properties of the fibers, the matrix and the fiber volume fraction, it is possible to estimate the stiffness of a ply reinforced with short fiber randomly dispersed in the plane of lamination. The approach is based on the analogy between a composite with randomly distributed reinforcements in the plane and a quasi-isotropic laminate of the type [0/90/ \pm 45$]$.

The longitudinal modulus $\mathrm{E}_{\mathrm{L}}$ and the transverse modulus $\mathrm{E}_{\mathrm{T}}$ of a ply reinforced by short unidirectional fibers are given by Equation. (1) and (2) proposed by Halpin-Tsaï (Halpin and Kardos, 1976).

$$
\frac{\mathrm{M}}{\mathrm{M}_{\mathrm{m}}}=\frac{1+\xi \cdot \eta \cdot \mathrm{V}_{\mathrm{f}}}{1-\eta \cdot \mathrm{V}_{\mathrm{f}}}
$$




$$
\eta=\frac{\frac{M_{f}}{M_{n}}-1}{\frac{M_{f}}{M_{m}}+\xi}
$$

where $\mathrm{M}=\mathrm{E}_{\mathrm{L}}$ or $\mathrm{E}_{\mathrm{T}}, \mathrm{M}_{\mathrm{f}}=\mathrm{E}_{\mathrm{fl}}$ or $\mathrm{E}_{\mathrm{ft}}$ and $\mathrm{m}, \mathrm{f}, \mathrm{L}$ and $\mathrm{T}$ correspond to matrix, fiber, longitudinal and transverse. $\mathrm{V}_{\mathrm{f}}$ is the fiber volume fraction and $\xi$ the form factor. For the longitudinal modulus, $\xi=2 \mathrm{~L} / \mathrm{d}$ where $\mathrm{L} / \mathrm{d}$ is the fiber aspect ratio. For the transverse modulus $\mathrm{E}_{\mathrm{T}}$, satisfactory results have been obtained with $\xi=2$ (Gibson, 2011). Baley has estimated the transverse modulus of flax fiber to be around 8 GPa by using micromechanical expressions (Baley et al., 2006). This latter value (8 GPa) will be used in the models presented here. Experimental Young's modulus of unitary fibers (Table 2) and matrix as well as the experimental aspect ratio of the fiber bundles were used were used for these calculations (Table 1).The fiber volume fractions were calculated from the fiber weight fraction taking a value of 1.50 as flax fiber density and 0.9 as PP/PPgMA density. The value 1.5 for flax fiber density is a typical value based on both the literature $($ Baley,2002) and inhouse experience.

Knowing the longitudinal and transverse stiffness of a ply reinforced by unidirectional fibers, the Young's modulus of a ply reinforced by randomly dispersed fibers (a hypothesis considered here in order to simplify the model) is then given by the following expression (Gibson, 2011):

$$
E_{m a t}=\frac{3}{8} E_{L}+\frac{5}{8} E_{T}
$$

where $\mathrm{E}_{\mathrm{L}}$ is the longitudinal modulus and $\mathrm{E}_{\mathrm{T}}$ the transverse modulus of the unidirectional ply, determined from expressions (1) and (2).

This approach is based on several hypotheses: a random distribution of the fibers in-plane, a homogenous distribution of the reinforcements, individual fibers (no bundles), no voids, a linear elastic behavior of the fibers and a perfect fiber/matrix bond. The model does not take into account the scatter in Young's modulus of the fibers, nor the aspect ratio of the fiber bundles. In this study, the non-wovens' anisotropy was also not considered. It is therefore necessary to compare model values to averaged experimental values between the MD and $\mathrm{CD}$ directions calculated as the sum of MD and CD properties divided by two. This would correspond to a $[\mathrm{MD} / \mathrm{CD}]$ alternate stacking sequence. 
Figure 7 shows the comparison between measured and predicted stiffness values of the composite materials as a function of fiber volume fraction. The model overestimates the stiffness of spunlaced and needlepunched composites by between 15 and $30 \%$, depending on fiber volume fraction, while it slightly underestimates the stiffness of fiber mat composites by between 5 and $15 \%$. The model tends to be closer to experimental values for the two lowest fiber volume fractions.

These discrepancies between experimental and predicted stiffness could be due to the validity of the model approach compared to the actual structure of the non-wovens. The model used here is rather simple and the morphology of the non-wovens is different from the ideal model organization. Indeed, the needlepunched fibers were curved and the spunlaced fibers were curled and highly entangled.

Nevertheless, the use of the micromechanical model discussed here provides a reasonable first estimate of the stiffness of the mat reinforced composites, but without taking into account the anisotropy of mechanical properties. In the case of needlepunched and spunlaced non-wovens composites, the experimental values are overestimated. The Halpin-Tsai equations were indeed developed for continuous fibre composites and are used here to estimate equivalent ply properties. Coupling these with Gibson's empirical expression for random short fibres (Equation 3) then allows the random distribution to be taken into account. This is a first approach, but these expressions are simple and widely used, and using them together appears to provide a good first estimation of composite properties even for these materials, so we believe these results may be helpful to readers looking for a tool to provide a first indication of non-woven composite performance.

For glass fiber reinforced plastics (GFRP), the mechanical properties are governed by several parameters e.g. fiber and matrix properties, fiber/matrix interface, fiber length distribution, fiber orientation, fiber volume fraction and homogeneity, void content, residual stress after process. The use of flax as a composite reinforcement implies additional considerations, in particular the level of separation of the bundles, fiber damage, fiber shape, and nonlinear behaviour of the fibers. Simple micromechanics models have been applied and provide a reasonable first estimate of stiffness of composites manufactured with these reinforcements, but they tend to overestimate properties.

The model could be improved to take into account the anisotropy of the mechanical properties of the composite and the efficiency of the reinforcement. More complex short fiber composite analytical models could be used., or numerical finite element methods could also be applied (Hine et al., 2002; Lusti et al., 2002). It 
would be also necessary to consider the nonlinear behavior of unitary flax fibers to further improve micromechanical model predictions.

\section{Conclusion}

In this study three non-woven fiber preforms have been evaluated and their performance as reinforcements for PP matrix composites has been assessed. Flax non-woven for composites reinforcement were manufactured by needlepunching, spunlacing and paper-making process. These provide reinforcements which are potentially very attractive for transport applications.

The structure of non-woven reinforcements is strongly dependent on the manufacturing route, and SEM has shown differences in the structure of the three reinforcements. The splitting of the bundles, their shape and orientation depend on the manufacturing technique. In spite of the out-of plane loads during consolidation the structures remain largely two-dimensional.

The preform fabrication process has only a small influence on the mechanical properties of individual fibers. A decrease in Young's modulus of 12\% is measured for fibers having undergone spunlacing or needlepunching. It is not clear what this is due to, but during spunlacing the action of water jets followed by drying introduces a hydrothermal loading in addition to mechanical stresses.

The three types of reinforcements show anisotropic in-plane properties highlighting a preferential orientation during manufacturing. The fibers or fiber bundles were not randomly distributed in the plane of the laminate.

Significant differences between the mechanical properties and behavior of the three composite materials are noted. The composites reinforced by mats show the highest tensile properties, as a result of straighter fibers, but these were the most anisotropic. Spunlaced and needlepunched materials show similar properties, the higher level of fiber separation of the former does not result in improved properties compared to needlepunched materials. This is attributed to more entanglements and loops in the spunlaced preforms.

Given the mechanical performance obtained for the three types of non-woven, structural applications can be envisaged for these composite materials. Apart from the mechanical properties, many other criteria are 
involved in choosing a technology e.g. availability of the process, capacity to mix different fibers, areal weight of the preform, drapability, volumes and costs.

This study has presented new data on non-woven flax fiber reinforcements and their behavior in PP matrix composites. The properties obtained are promising, but more work is needed to optimize the process and to understand the complex damage mechanisms in these materials.

\section{References}

Acar, M., Harper, J.F., 2000. Textile composites from hydro-entangled non-woven fabrics. Comput. Struct. 76, 105-114. doi:10.1016/S0045-7949(99)00167-4

Alimuzzaman, S., Gong, R. h., Akonda, M., 2014. Biodegradability of nonwoven flax fiber reinforced polylactic acid biocomposites. Polym. Compos. 35, 2094-2102. doi:10.1002/pc.22871

Alimuzzaman, S., Gong, R.H., Akonda, M., 2013. Nonwoven polylactic acid and flax biocomposites. Polym. Compos. 34, 1611-1619. doi:10.1002/pc.22561

Ausias, G., Bourmaud, A., Coroller, G., Baley, C., 2013. Study of the fibre morphology stability in polypropylene-flax composites. Polym. Degrad. Stab. 98, 1216-1224. doi:10.1016/j.polymdegradstab.2013.03.006

Baley, C., 2002. Analysis of the flax fibres tensile behaviour and analysis of the tensile stiffness increase. Compos. Part Appl. Sci. Manuf. 33, 939-948. doi:10.1016/S1359-835X(02)00040-4

Baley, C., Bourmaud, A., 2014. Average tensile properties of French elementary flax fibers. Mater. Lett. 122, 159-161. doi:10.1016/j.matlet.2014.02.030

Baley, C., Perrot, Y., Busnel, F., Guezenoc, H., Davies, P., 2006. Transverse tensile behaviour of unidirectional plies reinforced with flax fibres. Mater. Lett. 60, 2984-2987. doi:10.1016/j.matlet.2006.02.028

Bodros, E., Pillin, I., Montrelay, N., Baley, C., 2007. Could biopolymers reinforced by randomly scattered flax fibre be used in structural applications? Compos. Sci. Technol. 67, 462-470. doi:10.1016/j.compscitech.2006.08.024

Bos, H.L., Müssig, J., van den Oever, M.J.A., 2006. Mechanical properties of short-flax-fibre reinforced compounds. Compos. Part Appl. Sci. Manuf. 37, 1591-1604. doi:10.1016/j.compositesa.2005.10.011

Bourmaud, A., Ausias, G., Lebrun, G., Tachon, M.-L., Baley, C., 2013. Observation of the structure of a composite polypropylene/flax and damage mechanisms under stress. Ind. Crops Prod. 43, 225-236. doi:10.1016/j.indcrop.2012.07.030

Bourmaud, A., Baley, C., 2010. Effects of thermo mechanical processing on the mechanical properties of biocomposite flax fibers evaluated by nanoindentation. Polym. Degrad. Stab. 95, 1488-1494. doi:10.1016/j.polymdegradstab.2010.06.022

Bourmaud, A., Baley, C., 2007. Investigations on the recycling of hemp and sisal fibre reinforced polypropylene composites. Polym. Degrad. Stab. 92, 1034-1045. doi:10.1016/j.polymdegradstab.2007.02.018

Bourmaud, A., Gibaud, M., Lefeuvre, A., Morvan, C., Baley, C., 2015. Influence of the morphology characters of the stem on the lodging resistance of Marylin flax. Ind. Crops Prod. 66, 27-37. doi:10.1016/j.indcrop.2014.11.047

Charlet, K., Béakou, A., 2011. Mechanical properties of interfaces within a flax bundle - Part I: Experimental analysis. Int. J. Adhes. Adhes. 31, 875-881. doi:10.1016/j.ijadhadh.2011.08.008

Chen, Y., Müller, D.H., Nießen, K., Müssig, J., 2008. Spunlaced Flax/Polypropylene Nonwoven as Auto Interior Material: Mechanical Performance. J. Ind. Text. 38, 69 -86. doi:10.1177/1528083707087832 
Coroller, G., Lefeuvre, A., Le Duigou, A., Bourmaud, A., Ausias, G., Gaudry, T., Baley, C., 2013. Effect of flax fibres individualisation on tensile failure of flax/epoxy unidirectional composite. Compos. Part Appl. Sci. Manuf. 51, 62-70. doi:10.1016/j.compositesa.2013.03.018

Defoirdt, N., Biswas, S., Vriese, L.D., Tran, L.Q.N., Acker, J.V., Ahsan, Q., Gorbatikh, L., Vuure, A.V., Verpoest, I., 2010. Assessment of the tensile properties of coir, bamboo and jute fibre. Compos. Part Appl. Sci. Manuf. 41, 588-595. doi:10.1016/j.compositesa.2010.01.005

Ericson, M., Berglund, L., 1992. Deformation and fracture of glass-mat-reinforced polypropylene. Compos. Sci. Technol. 43, 269-281. doi:10.1016/0266-3538(92)90098-N

Fages, E., Gironés, S., Sánchez-Nacher, L., García-Sanoguera, D., Balart, R., 2012. Use of wet-laid techniques to form flax-polypropylene nonwovens as base substrates for eco-friendly composites by using hot-press molding. Polym. Compos. 33, 253-261. doi:10.1002/pc.22147

Garkhail, S.K., Heijenrath, R.W.H., Peijs, T., 2000. Mechanical Properties of Natural-Fibre-Mat- Reinforced Thermoplastics based on Flax Fibres and Polypropylene. Appl. Compos. Mater. 7, 351-372.

Gibson, R.F., 2011. Principles of Composite Material Mechanics, Third Edition, 3 edition. ed. CRC Press, Boca Raton, Fla.

Gorshkova, T.A., Sal'nikov, V.V., Chemikosova, S.B., Ageeva, M.V., Pavlencheva, N.V., van Dam, J.E.G., 2003. The snap point: a transition point in Linum usitatissimum bast fiber development. Ind. Crops Prod. 18, 213-221. doi:10.1016/S0926-6690(03)00043-8

Gourier, C., Le Duigou, A., Bourmaud, A., Baley, C., 2014. Mechanical analysis of elementary flax fibre tensile properties after different thermal cycles. Compos. Part Appl. Sci. Manuf. 64, 159-166. doi:10.1016/j.compositesa.2014.05.006

Halpin, J.C., Kardos, J.L., 1976. The Halpin-Tsai equations: A review. Polym. Eng. Sci. 16, 344-352. doi:10.1002/pen.760160512

Hine, P.J., Rudolf Lusti, H., Gusev, A.A., 2002. Numerical simulation of the effects of volume fraction, aspect ratio and fibre length distribution on the elastic and thermoelastic properties of short fibre composites. Compos. Sci. Technol. 62, 1445-1453. doi:10.1016/S0266-3538(02)00089-1

Huda, M.S., Drzal, L.T., Ray, D., Mohanty, A.K., Misra, M., 2008. Natural-fiber composites in the automotive sector, in: Pickering, K.L. (Ed.), Properties and Performance of Natural Fibre Composites. Woodhead Pub. ; Maney Pub. ; CRC Press, Cambridge, England; [England?]; Boca Raton, FL, pp. 221-268.

Karger-Kocsis, J., Harmia, T., Czigány, T., 1995. Comparison of the fracture and failure behavior of polypropylene composites reinforced by long glass fibers and by glass mats. Compos. Sci. Technol. 54, 287-298. doi:10.1016/0266-3538(95)00068-2

Kies, J.., 1962. Maximum strains in the resin of fiberglass composites.

Le Duigou, A., Davies, P., Baley, C., 2011. Environmental Impact Analysis of the Production of Flax Fibres to be Used as Composite Material Reinforcement. J. Biobased Mater. Bioenergy 5, 153-165. doi:10.1166/jbmb.2011.1116

Lefeuvre, A., Bourmaud, A., Morvan, C., Baley, C., 2014. Tensile properties of elementary fibres of flax and glass: Analysis of reproducibility and scattering. Mater. Lett. 130, 289-291. doi:10.1016/j.matlet.2014.05.115

Lindhagen, J., Berglund, L., 1998. Microscopical damage mechanisms in glass fiber reinforced polypropylene. J. Appl. Polym. Sci. 69, 1319-1327. doi:10.1002/(SICI)1097-4628(19980815)69:7<1319::AIDAPP6>3.0.CO;2-H

Lusti, H.R., Hine, P.J., Gusev, A.A., 2002. Direct numerical predictions for the elastic and thermoelastic properties of short fibre composites. Compos. Sci. Technol. 62, 1927-1934. doi:10.1016/S02663538(02)00106-9

Martin, N., Davies, P., Baley, C., 2014. Comparison of the properties of scutched flax and flax tow for composite material reinforcement. Ind. Crops Prod. 61, 284-292. doi:10.1016/j.indcrop.2014.07.015

Martin, N., Mouret, N., Davies, P., Baley, C., 2013. Influence of the degree of retting of flax fibers on the tensile properties of single fibers and short fiber/polypropylene composites. Ind. Crops Prod. 49, 755-767. doi:10.1016/j.indcrop.2013.06.012 
Miao, M., Pierlot, A.P., Millington, K., Gordon, S.G., Best, A., Clarke, M., 2013. Biodegradable mulch fabric by surface fibrillation and entanglement of plant fibres. Text. Res. J. 0040517513483861. doi: $10.1177 / 0040517513483861$

Mieck, K.-P., Lützkendorf, R., Reussmann, T., 1996. Needle-Punched hybrid nonwovens of flax and ppfiberstextile semiproducts for manufacturing of fiber composites. Polym. Compos. 17, 873-878. doi: $10.1002 /$ pc. 10680

Morvan, C., Andème-Onzighi, C., Girault, R., Himmelsbach, D.S., Driouich, A., Akin, D.E., 2003. Building flax fibres: more than one brick in the walls. Plant Physiol. Biochem. 41, 935-944. doi:10.1016/j.plaphy.2003.07.001

Oksman, K., 2000. Mechanical Properties of Natural Fibre Mat Reinforced Thermoplastic. Appl. Compos. Mater. 7, 403-414. doi:10.1023/A:1026546426764

Pillin, I., Kervoelen, A., Bourmaud, A., Goimard, J., Montrelay, N., Baley, C., 2011. Could oleaginous flax fibers be used as reinforcement for polymers? Ind. Crops Prod. 34, 1556-1563. doi:10.1016/j.indcrop.2011.05.016

Roussière, F., Baley, C., Godard, G., Burr, D., 2012. Compressive and Tensile Behaviours of PLLA Matrix Composites Reinforced with Randomly Dispersed Flax Fibres. Appl. Compos. Mater. 19, 171-188. doi:10.1007/s10443-011-9189-8

Russell, S., 2006. Handbook of Nonwovens. Woodhead Publishing.

Sato, N., Kurauchi, T., Sato, S., Kamigaito, O., 1991. Microfailure behaviour of randomly dispersed short fibre reinforced thermoplastic composites obtained by direct SEM observation. J. Mater. Sci. 26, 3891-3898. doi:10.1007/BF01184987

Schneider, C.A., Rasband, W.S., Eliceiri, K.W., 2012. NIH Image to ImageJ: 25 years of image analysis. Nat. Methods 9, 671-675. doi:10.1038/nmeth.2089

Shah, D.U., 2013. Developing plant fibre composites for structural applications by optimising composite parameters: a critical review. J. Mater. Sci. 48, 6083-6107. doi:10.1007/s10853-013-7458-7

Stamboulis, A., Baillie, C.A., Garkhail, S.K., van Melick, H.G.H., Peijs, T., 2000. Environmental Durability of Flax Fibres and their Composites based on Polypropylene Matrix. Appl. Compos. Mater. 7, 273-294. doi:10.1023/A:1026581922221

Xue, D., Miao, M., Hu, H., 2011. Permeability anisotropy of flax nonwoven mats in vacuum-assisted resin transfer molding. J. Text. Inst. 102, 612-620. doi:10.1080/00405000.2010.504566 
Table 1 Morphology of the fibers of the three non-wovens

Table 2 Mean tensile properties of the elementary flax fibers. N: sample size. Comparison with literature values.

Table 3 Results of image analysis performed on SEM images of the cross section of composites.

Table 4 Mean tensile properties of the composites for direction MD

Table 5 Mean tensile properties of the composites for direction CD

Table 6 Tensile properties of flax non-woven reinforced polypropylene reported in the literature

Table 1 Morphology of the fibers of the three non-wovens

\begin{tabular}{cccc}
\hline Material & Length $(\mathrm{mm})$ & Diameter $(\mu \mathrm{m})$ & Aspect ratio L/d \\
\hline Spunlaced & $25 \pm 3$ & $25 \pm 14$ & $\sim 1000$ \\
Needlepunched & $35 \pm 5$ & $38 \pm 28$ & $\sim 1000$ \\
Mat & $10 \pm 1$ & $51 \pm 49$ & $\sim 200$ \\
\hline
\end{tabular}

Table 2 Mean tensile properties of the elementary flax fibers. N: sample size.

Comparison with literature values.

\begin{tabular}{cccccc}
\hline Batch & $\begin{array}{c}\text { Sample } \\
\text { Size }\end{array}$ & $\begin{array}{c}\text { Diameter } \\
(\mu \mathrm{m})\end{array}$ & $\begin{array}{c}\text { Young’s } \\
\text { Modulus } \\
(\mathrm{MPa})\end{array}$ & $\begin{array}{c}\text { Maximum } \\
\text { strength } \\
(\mathrm{MPa})\end{array}$ & $\begin{array}{c}\text { Elongation at } \\
\text { break } \\
(\%)\end{array}$ \\
\hline Raw fibers & 53 & $15.2 \pm 2.8$ & $58 \pm 15$ & $1048 \pm 384$ & $2.0 \pm 0.6$ \\
Spunlaced & 59 & $15.9 \pm 3.3$ & $51 \pm 15$ & $916 \pm 347$ & $1.9 \pm 0.5$ \\
Needlepunched & 54 & $15.5 \pm 2.9$ & $52 \pm 13$ & $932 \pm 356$ & $1.9 \pm 0.4$ \\
\hline Roussière et al. (2012) & 54 & $15.3 \pm 1.5$ & $48 \pm 18$ & $1062 \pm 432$ & $2.3 \pm 0.8$ \\
\hline Baley and Bourmaud (2014) & 2954 & 16.8 & 52 & 945 & 2.1 \\
\hline
\end{tabular}


Table 3 Results of image analysis performed on SEM images of the cross section of composites.

\begin{tabular}{ccccc}
\hline Non-woven & $\begin{array}{c}\text { Void } \\
\text { content } \\
(\%)\end{array}$ & $\begin{array}{c}\text { Number of } \\
\text { objects }\end{array}$ & $\begin{array}{c}\text { Mean cross } \\
\text { section area } \\
\left(\mu \mathrm{m}^{2}\right)\end{array}$ & $\begin{array}{c}\text { Area range } \\
\left(\mu \mathrm{m}^{2}\right)\end{array}$ \\
\hline Mat & 0.42 & 4788 & 551 & $20-32558$ \\
Needlepunched & 0.35 & 6845 & 408 & $20-26554$ \\
Spunlaced & 0.31 & 8857 & 307 & $20-16700$ \\
\hline
\end{tabular}

Table 4 Mean tensile properties of the composites for direction MD

\begin{tabular}{ccccc}
\hline Material & $\begin{array}{c}\text { Fibre } \\
\text { volume } \\
\text { fraction } \\
(\%)\end{array}$ & $\begin{array}{c}\text { Young's } \\
\text { Modulus } \\
(\mathrm{MPa})\end{array}$ & $\begin{array}{c}\text { Maximum } \\
\text { strength } \\
(\mathrm{MPa})\end{array}$ & $\begin{array}{c}\text { Elongation at } \\
\text { break } \\
(\%)\end{array}$ \\
\hline PP & 0 & $1729 \pm 110$ & $22 \pm 0.2$ & $10.9 \pm 1.8$ \\
\hline Spunlaced MD & 12.3 & $3035 \pm 169$ & $38 \pm 3$ & $2.9 \pm 0.2$ \\
& 21.7 & $4813 \pm 115$ & $51 \pm 1$ & $2.4 \pm 0.2$ \\
& 29.1 & $5632 \pm 251$ & $65 \pm 1$ & $2.3 \pm 0.1$ \\
& 37.8 & $7190 \pm 216$ & $75 \pm 1$ & $2.4 \pm 0.2$ \\
\hline \multirow{2}{*}{ Needlepunched MD } & 13.4 & $3299 \pm 238$ & $33 \pm 1$ & $2.5 \pm 0.2$ \\
& 19.4 & $3601 \pm 166$ & $41 \pm 3$ & $2.7 \pm 0.1$ \\
& 27.7 & $4485 \pm 237$ & $56 \pm 3$ & $2.4 \pm 0.1$ \\
& 36.9 & $6484 \pm 216$ & $57 \pm 1$ & $1.7 \pm 0.1$ \\
\hline \multirow{2}{*}{ Mat MD } & 12.5 & $3852 \pm 204$ & $40 \pm 5$ & $1.9 \pm 0.3$ \\
& 19.5 & $5732 \pm 318$ & $51 \pm 7$ & $1.4 \pm 0.2$ \\
& 28.1 & $8024 \pm 383$ & $74 \pm 5$ & $1.5 \pm 0.1$ \\
& 36.9 & $9569 \pm 681$ & $93 \pm 4$ & $1.7 \pm 0.1$ \\
\hline
\end{tabular}


Table 5 Mean tensile properties of the composites for direction CD

\begin{tabular}{ccccc}
\hline Material & $\begin{array}{c}\text { Fibre volume } \\
\text { fraction } \\
(\%)\end{array}$ & $\begin{array}{c}\text { Young's } \\
\text { Modulus } \\
(\mathrm{MPa})\end{array}$ & $\begin{array}{c}\text { Maximum } \\
\text { strength } \\
(\mathrm{MPa})\end{array}$ & $\begin{array}{c}\text { Elongation at } \\
\text { break } \\
(\%)\end{array}$ \\
\hline PP & 0 & $1729 \pm 110$ & $21.7 \pm 0.2$ & $10.94 \pm 1.76$ \\
\hline Spunlaced CD & 12.7 & $3077 \pm 162$ & $33 \pm 1$ & $3.7 \pm 0.1$ \\
& 20.4 & $3448 \pm 194$ & $37 \pm 1$ & $3.3 \pm 0.2$ \\
& 27.6 & $3436 \pm 259$ & $42 \pm 1$ & $3.3 \pm 0.2$ \\
\hline \multirow{2}{*}{ Needlepunched CD } & 36.8 & $4591 \pm 157$ & $50 \pm 1$ & $3.0 \pm 0.2$ \\
& 13.9 & $3542 \pm 325$ & $37 \pm 2$ & $2.3 \pm 0.1$ \\
& 21.6 & $4820 \pm 340$ & $49 \pm 1$ & $2.1 \pm 0.1$ \\
& 28.7 & $5443 \pm 216$ & $65 \pm 1$ & $2.3 \pm 0.1$ \\
& 38.6 & $7433 \pm 329$ & $73 \pm 2$ & $1.9 \pm 0.3$ \\
\hline \multirow{2}{*}{ Mat CD } & 13.3 & $3349 \pm 366$ & $29 \pm 3$ & $2.1 \pm 0.4$ \\
& 21.5 & $3989 \pm 217$ & $38 \pm 3$ & $1.9 \pm 0.2$ \\
& 27.8 & $5478 \pm 545$ & $55 \pm 4$ & $1.7 \pm 0.1$ \\
& 36.5 & $6325 \pm 214$ & $53 \pm 1$ & $1.6 \pm 0.1$ \\
\hline
\end{tabular}


Table 6 Tensile properties of flax non-woven reinforced polypropylene reported in the literature.

\begin{tabular}{|c|c|c|c|c|}
\hline Materials & $\begin{array}{l}\text { Fibre volume } \\
\text { fraction } \\
(\%)\end{array}$ & $\begin{array}{c}\text { Young's Modulus } \\
\text { (MPa) }\end{array}$ & $\begin{array}{l}\text { Maximum } \\
\text { strength } \\
\text { (MPa) }\end{array}$ & $\begin{array}{l}\text { Elongation } \\
\text { at break } \\
(\%)\end{array}$ \\
\hline Spunlaced (average) & 36.8 & 5891 & 62.5 & $2.4-3$ \\
\hline Needlepunched (average) & 38.6 & 6959 & 65 & $1.7-1.9$ \\
\hline Mat (average) & 36.5 & 7947 & 73 & $1.6-1.7$ \\
\hline $\begin{array}{l}\text { Spunlaced flax/PP } \\
\text { (Chen et al.. 2008) }\end{array}$ & 37 & $1405 \pm 101$ & $28.20 \pm 2.8$ & ND \\
\hline $\begin{array}{l}\text { Spunlaced PET/ polyester } \\
\text { (Acar and Harper. 2000) }\end{array}$ & 33 & $\sim 1000$ & $\sim 65$ & ND \\
\hline $\begin{array}{l}\text { Flax mat/PP/PPgMA } \\
\text { (Bodros et al.. 2007) }\end{array}$ & 30 & $5681 \pm 373$ & $73.6 \pm 1.2$ & 1.5 \\
\hline $\begin{array}{l}\text { Flax mat/PP/PPgMA } \\
\text { (Bos et al.. 2006) }\end{array}$ & 37 & $\sim 8500$ & $\sim 65$ & ND \\
\hline $\begin{array}{l}\text { Needlepunched Flax/PP/PPgMA } \\
\text { (Garkhail et al.. 2000) }\end{array}$ & $\sim 45$ & $\sim 11000$ & $\sim 50$ & ND \\
\hline $\begin{array}{l}\text { Needlepunched Flax/PP/PPgMA } \\
\text { (Mieck et al.. 1996) }\end{array}$ & $\sim 42$ & $\sim 12000$ & $\sim 115$ & ND \\
\hline
\end{tabular}


Figure 1 Temperature and pressure cycle used for composites manufacturing

Figure 2 SEM micrographs of the surface and cross section of dry non-wovens A and B: needlepunched, C and D: spunlaced, E and F: Mat

Figure 3SEM micrographs of the cross section of composites samples in MD direction. $\mathrm{V}_{\mathrm{f}}=28.6$.

A: Spunlaced, B: Needlepunched, C: Mat.

Figure 4 Tensile behavior of the composite materials reinforced with flax non-wovens in the MD direction. A: Needlepunched, B: Spunlaced, C: Mat.

Figure 5 SEM observations of failure surface of composites tensile specimens in direction MD. A and B: Spunlaced, C and D: Needlepunched. E and F: Mat. Vf=28.6\%.

Figure 6 Mean of mechanical properties between MD and CD directions.

Figure 7 Measured and predicted stiffness values of the composite materials as a function of fiber volume fraction.

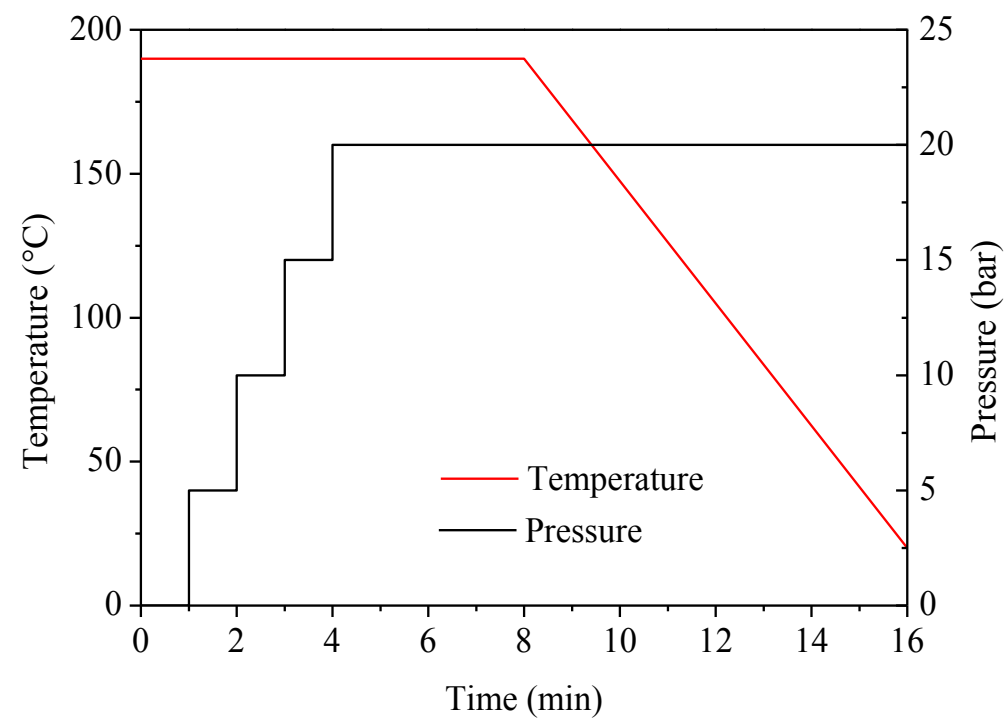

Figure 1 Temperature and pressure cycle used for composites manufacturing 

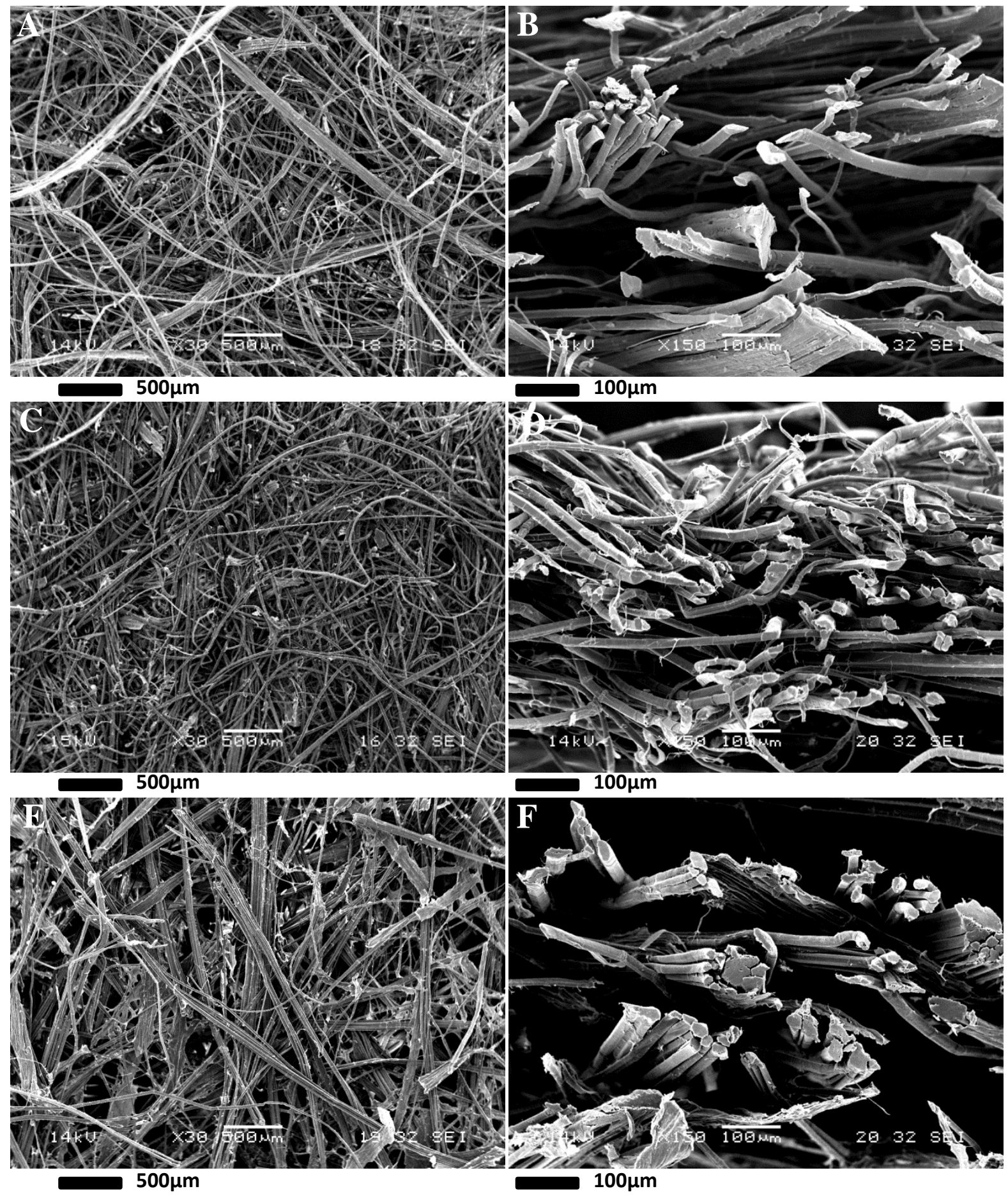

Figure 2 SEM micrographs of the surface and cross section of dry non-wovens A and B: needlepunched, C and D: spunlaced, E and F: Mat 

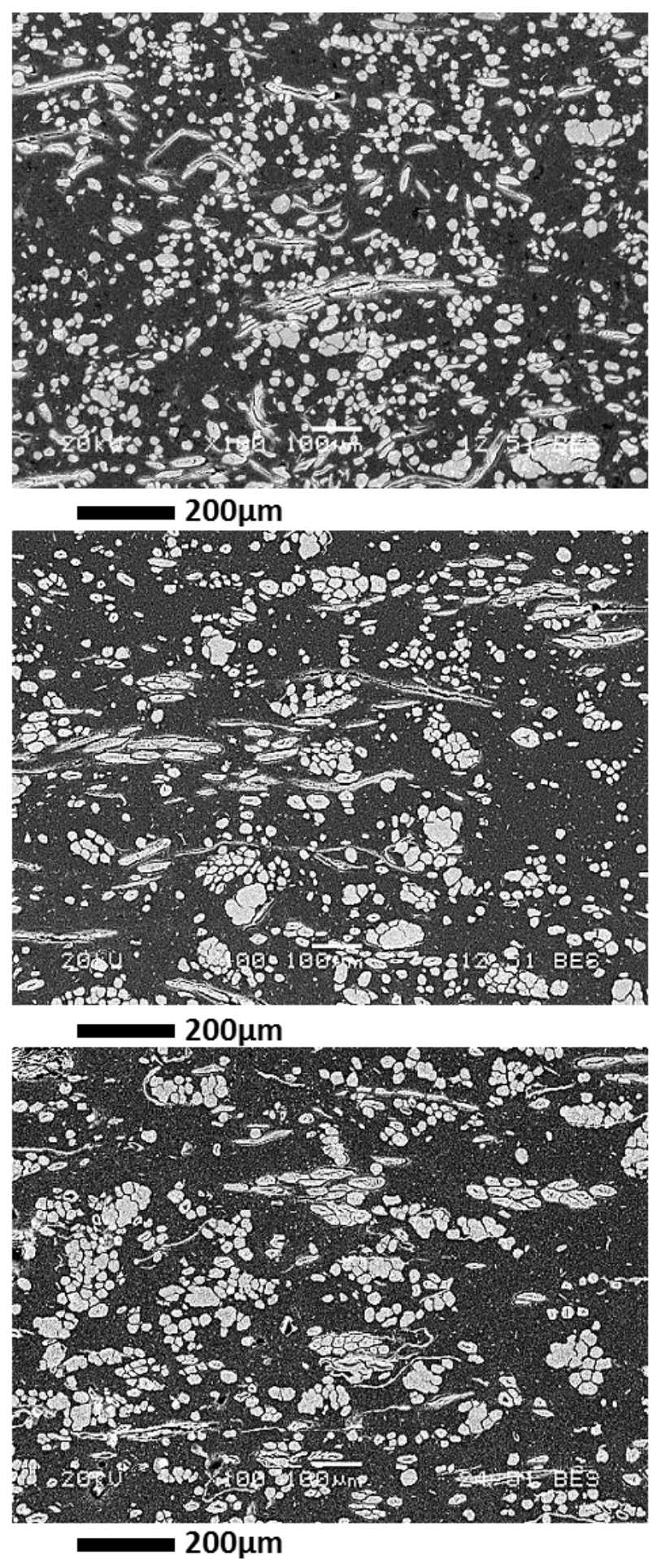

Figure 3SEM micrographs of the cross section of composites samples in $M D$ direction. $V_{\mathrm{f}}=\mathbf{2 8 . 6}$. A: Spunlaced, B: Needlepunched, C: Mat. 

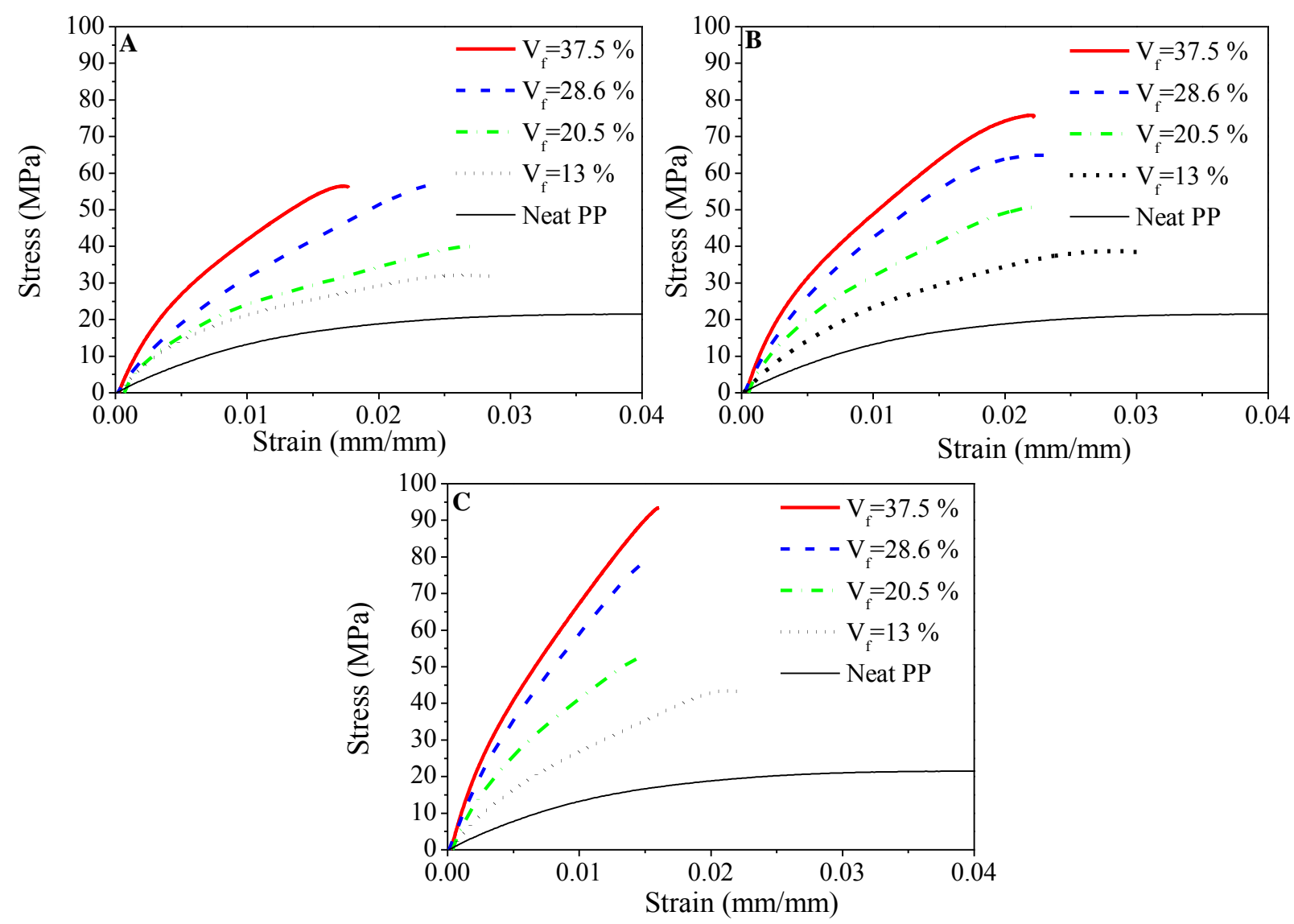

Figure 4 Tensile behavior of the composite materials reinforced with flax non-wovens in the MD direction. A: Needlepunched, B: Spunlaced, C: Mat. 

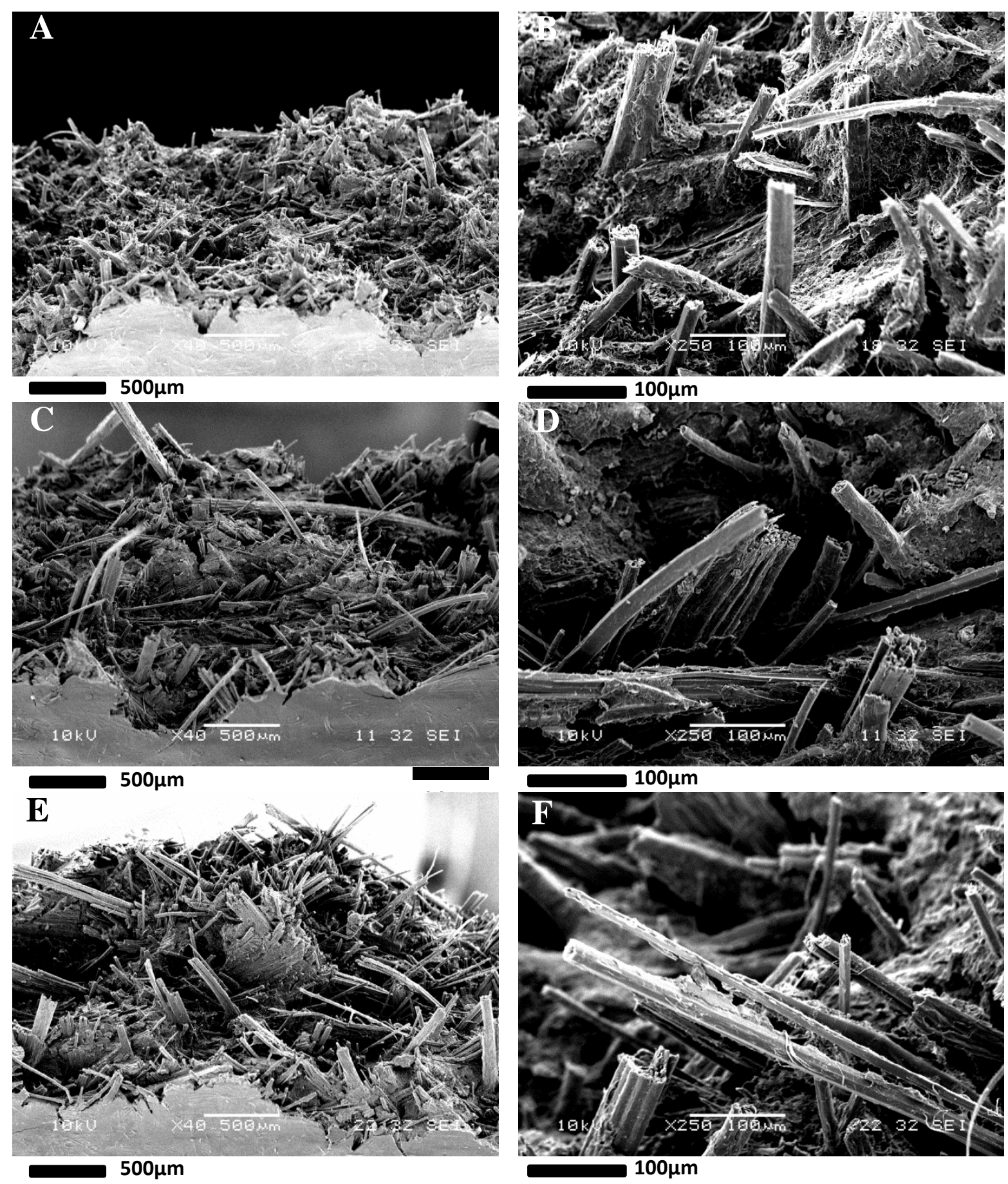

Figure 5 SEM observations of failure surface of composites tensile specimens in direction MD. A and B: Spunlaced, C and D: Needlepunched. E and F: Mat. Vf=28.6 \%. 


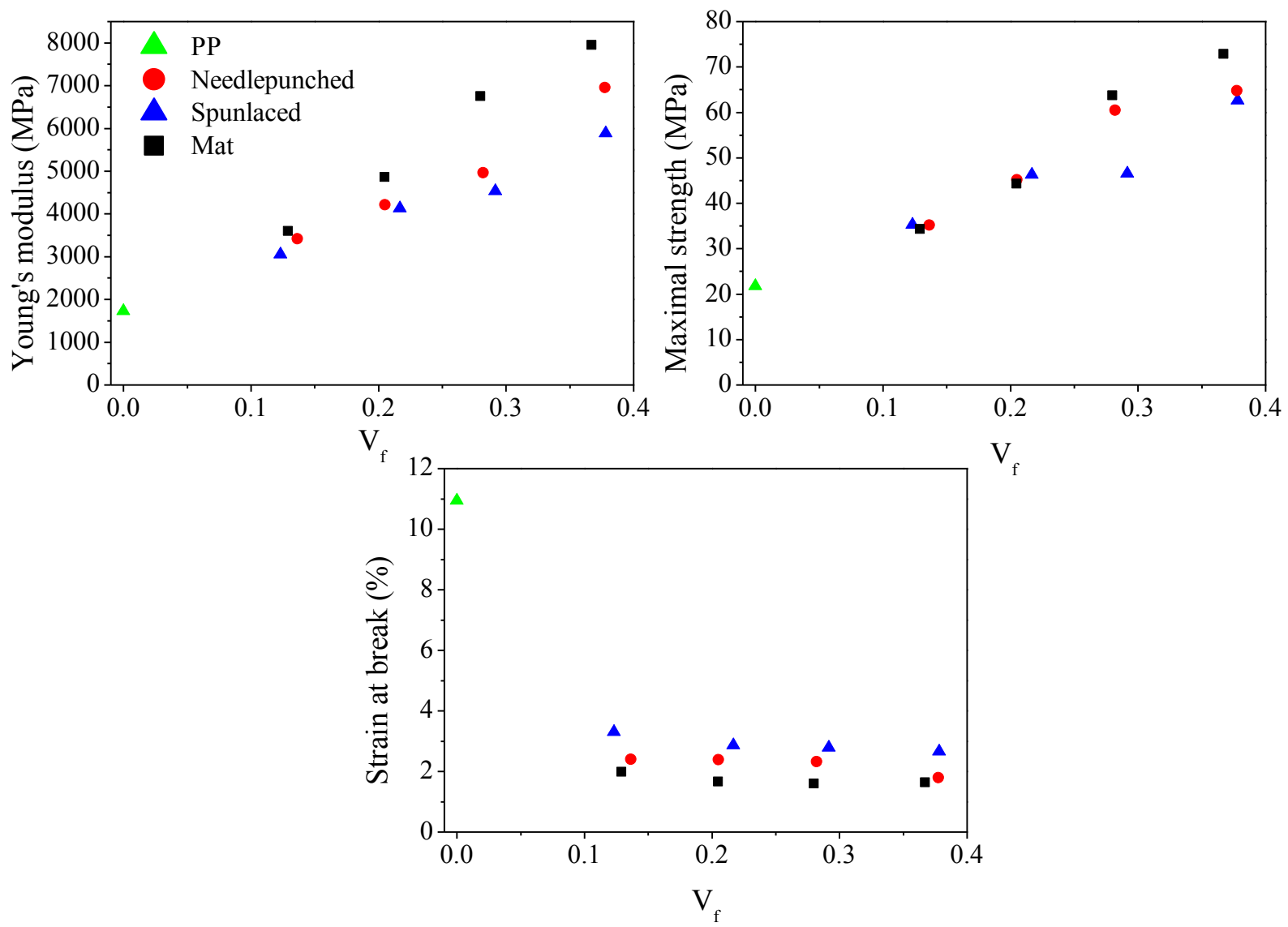

Figure 6 Mean of mechanical properties between MD and CD directions. 

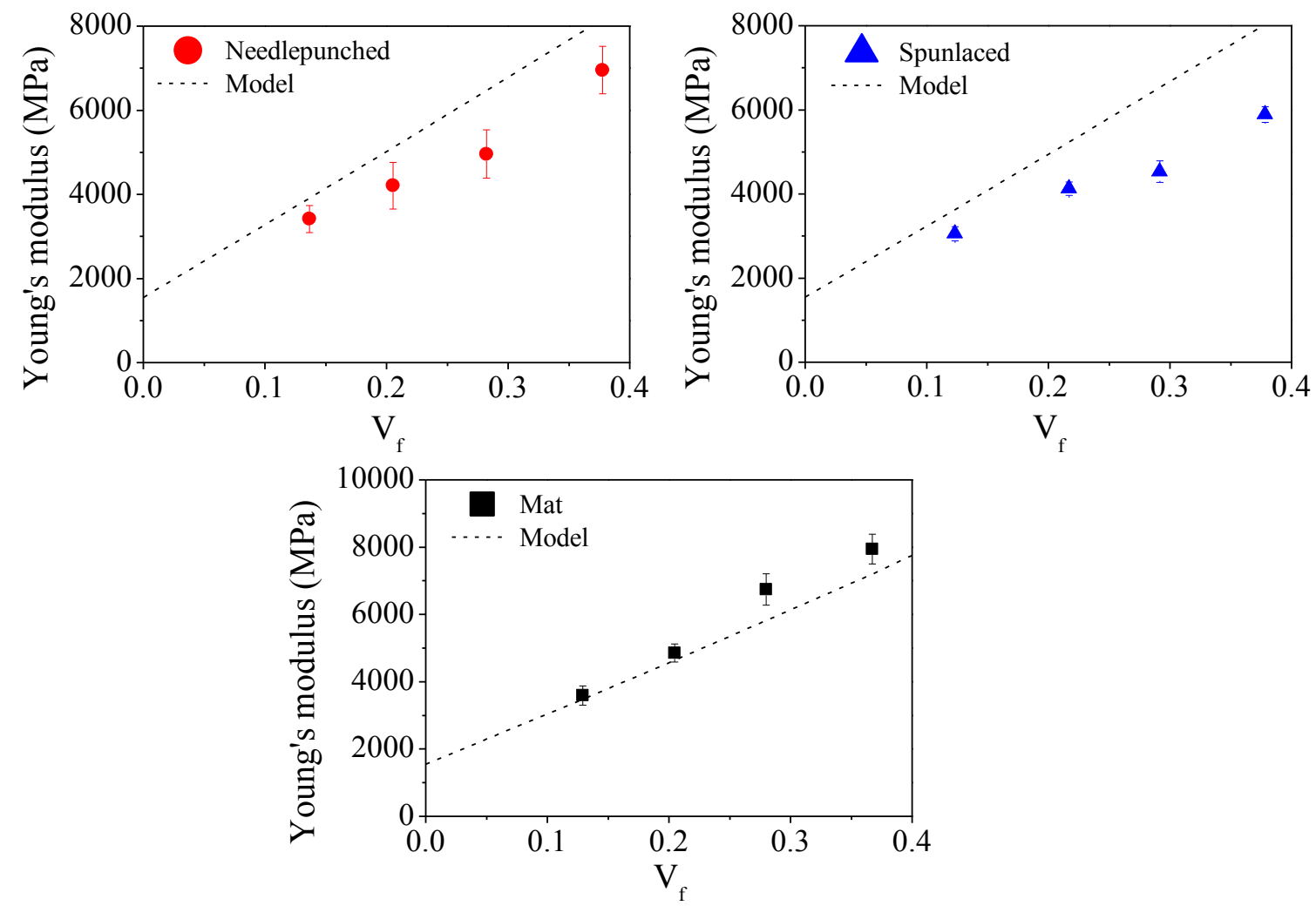

Figure 7 Measured and predicted stiffness values of the composite materials as a function of fiber volume fraction. 